\title{
Pragmatic Failure, Epistemic Injustice and Epistemic Vigilance
}

\section{Introduction}

If human verbal communication faces many challenges, risks and problems when individuals use their native or first language (L1) to interact, the number of challenges, risks and problems may exponentially increase when they resort to a second language (L2), which they are learning or have learnt. When used in intercultural contexts to ensure communication between speakers of different L1s and backgrounds, that L2 becomes a lingua franca (LF), which, if not fully mastered by at least one of the interacting parties, may render communication an endeavour prone to mistakes and misunderstandings (Deterding, 2013; Mustajoki, 2012; Weigand, 1999; Zamborlin, 2007). In the field of pragmatics, the misunderstandings native and non-native speakers may experience when using a language other than their L1 are termed pragmatic failures (Thomas, 1983).

Pragmatic failures have been reported to result in rather funny and anecdotal misunderstandings, although they may also surprise, puzzle, astonish, frustrate, upset or embarrass interlocutors (Beebe and Takahashi, 1989; Thomas, 1983, 1984). In extreme cases, these failures may even give rise to cultural friction and interactive conflict amenable to communication breakdown. But more importantly for the purpose of this paper, pragmatic failures may be at the root of unfair and unjustified attribution of beliefs, intentions, personality traits, feelings and attitudes -i.e., mental states that will henceforth be referred to as propositional attitudes (PAs) for short, following Garfield et al. (2001, p. 495). Although the outcomes of such attributions depend on the degree of 'error' or flaw perceived (Riley, 2006, p. 314), if communities of practice or cultural groups, or members thereof, repeatedly make erroneous attributions of beliefs and PAs and perpetuate them over time, negative 
labelling, stereotypes -i.e., '[...] widely held associations between a given social group and one or more attributes' (Fricker, 2007, p. 41)- and/or even undesirable discrimination may ensue (Boxer, 2002; Kasanga, 2001; Kasanga and Lwanga-Lumu, 2007).

The term 'pragmatic failure' seems to have been mostly restricted to describe the infelicitous mistakes that L2 learners and LF users make when they perform as speakers. However, individuals also make plenty of interpretive mistakes when they perform as hearers (Padilla Cruz, 2012a, 2013a, 2013b; Yus Ramos, 1999a, 1999b). They may incorrectly decode, parse and disambiguate utterances, as well as wrongly narrow or broaden the meaning of their lexical items, so they may build erroneous lower-level explicatures (Carston, 2002; Sperber and Wilson, 1986, 1995) ${ }^{1}$. Hearers may also construct inadequate higher-level explicatures if they embed the material in the lower-level explicature under inappropriate speech-act or propositional-attitude descriptions as a result of misinterpreting intonation or paralanguage (Sperber and Wilson, 1986, 1995; Wharton, 2009). Moreover, hearers may also lack the cultural knowledge that enables them to make sense of what other people say, e.g., information about their communicative practices and conventions in specific interactive contexts. Alternatively, their knowledge about communicative practices and conventions may slightly or significantly differ from the knowledge that informs and guides other people's communicative behaviour. Consequently, hearers may fail to arrive at some expected implicatures or reach undesired conclusions about other people's communicative behaviour. Such conclusions underlie on many occasions labelling and stereotypes, as they negatively bias hearers' perceptions of other individuals' beliefs, PAs and personality traits.

This paper seeks to account for the origin of some of the negative outcomes of individuals' wrong interpretations of communicative behaviour in L2/LF interaction, namely, stereotypes and negative labelling. It also suggests an answer to the question of how

\footnotetext{
${ }^{1}$ A lower-level explicature is a logical form -i.e., an organised set of concepts- which has been pragmatically enriched with contextual material (Sperber and Wilson, 1995).
} 
individuals could avoid or overcome them. In order to do this, it firstly defines pragmatic failure, illustrates its types and explains how they arise (Section 2). Since this paper adheres to the relevance-theoretic approach to communication (Sperber and Wilson, 1986, 1995; Wilson and Sperber, 2002, 2004), it argues that negative stereotypes and labelling originating from pragmatic failure are a by-product of (i) the relevance-driven processes taking place in comprehension, which try to make sense of communicative behaviour that hearers perceive as deviating or 'peculiar', and (ii) an alleged lack of competence attributed to other LF users (Section 3). This leads to a reflection on the role of mindreading in hearers' interpretation of L2 learners and LF users' alleged pragmatic incompetence and the discrepancies hearers detect between their own cultural knowledge and expectations about communicative behaviour in specific settings and L2 learners and LF users' deviating behaviour (Section 4). Next, this paper addresses an extreme effect of L2 learners and LF users' real or apparent pragmatic incompetence: pragmatic-hermeneutical injustice, a concept that is coined in this paper in order to describe a sub-type of what in social epistemology is known as epistemic injustice and, more specifically, hermeneutical injustice (Fricker, 2003, 2006, 2007). It is argued that stereotypes and negative labelling might have their roots in repeated injustices of this type (Section 5). Then, the paper proceeds to analyse the role that epistemic vigilance (Mascaro and Sperber, 2009; Sperber et al., 2010) should have in communication through an L2/LF (Section 6). It suggests that some form of vigilance directed towards interpretations, which could be termed hermeneutical vigilance, may prevent the interpretation of authentic or seeming pragmatic mistakes from resulting in stereotypes and negative labelling if it triggers a shift from a simple and straightforward processing strategy to a more sophisticated one. To conclude, this paper summarises its main arguments and suggests some avenues for future research. 


\section{Pragmatic Failure in L2/LF Interaction}

Pragmatic failures are those misunderstandings which arise as a consequence of '[...] the inability to understand what is meant by what is said' (Thomas, 1983, p. 93). Briefly stated, this term alludes to those misunderstandings resulting from the speakers' selection of inappropriate communicative strategies or abidance by differing socio-cultural principles. Although the term seems to have been restricted solely to intercultural communication and, typically, to interaction between native and non-native speakers of a language, it must be understood as referring to misunderstandings arising '[...] whenever two speakers fail to understand each other's intentions' (Blum-Kulka and Olshtain, 1986, p. 166), i.e., whenever two individuals fail to arrive at expected, desired or correct interpretations. In fact, Yus Ramos (1999a, 1999b) exemplifies various types of misunderstandings that may often arise between members of the same cultural group when these take wrong inferential steps. Even though pragmatic failure is ubiquitous and may affect intracultural communication, this paper centres on pragmatic failure in intercultural contexts in which interlocutors use an LF.

Two types of pragmatic failure are usually distinguished in the literature after Leech's (1983) distinction between pragmalinguistics and sociopragmatics. The first type is pragmalinguistic failure (Thomas, 1983) and it arises when the speakers' communicative behaviour turns out to be unsuitable to a context because they:

a) inadequately transfer and extend L1 strategies,

b) simplify the range of strategies or conversational moves commonly used to accomplish some speech acts,

c) arrange the strategies or conversational moves making up some speech-act sequences in orders that differ from those in which other speakers would arrange them.

d) select wrong suprasegmental/prosodic features or inadequate paralinguistic signals 
(Hale, 1996, 1997; House, 1990; Kasper, 1992; Olshtain and Cohen, 1990; Riley, 1989, 2006; Tannen, 1984; Tran, 2006).

The causes of pragmalinguistic failure are manifold and include having learnt an L2/LF in a foreign language context where individuals lack opportunities for real contact with and interaction in it, excessive reliance on the 'textbook/classroom language' to which they are exposed or anxiety to communicate as clearly as possible (e.g., Hong, 1997; Hurley, 1992).

The vast literature on interlanguage and developmental pragmatics offers plenty of examples of this type of pragmatic failure. Among others, compliments are speech acts frequently liable to intercultural misunderstandings. For instance, Han (1992) reports that Korean learners of English interpreted a compliment-response like 'really?' as a request for reassurance or repetition, rather than as a compliment acceptance because of their L1 tendency not to use this type of responses. Nelson, Al-Batal and Echols (1996) comment that the compliment responses of Syrian Arabic learners of English were more elaborate than the responses of their English interlocutors, which somehow puzzled the latter. Likewise, Nelson, El Bakary and Al Batal (1996) illustrate that Egyptian learners of English resorted to very innovative and creative comparisons or metaphors when paying compliments, which also sounded 'weird' to their American interlocutors. Another locus for pragmalinguistic failures is small talk or phatic communion. For example, Nine-Curt (1977), Scarcella (1979) and Pavlidou (1994, 1998) note that some Americans, Britons or Germans regarded their Puerto Rican or Greek interlocutors' usage of personal phatic questions aimed at establishing rapport when beginning a conversation as bald, excessive and too invasive.

The second type of pragmatic failure is sociopragmatic failure (Thomas, 1983). It originates when interlocutors' norms or rules of speaking (significantly) differ, or when individuals unknowingly abide by those of their L1 and extrapolate them to interaction in another language (Beebe et al., 1990; Riley, 1989, 2006; Takahashi and Beebe, 1987; 
Wolfson, 1989) ${ }^{2}$. Sociopragmatic failures reveal cross-linguistic influences upon interlocutors' verbal production and comprehension from their L1 or any other language they know (Kasper, 1992; Kasper and Blum-Kulka, 1993; Takahashi and Beebe, 1993). Those influences may increase if they are not very acquainted with the L2/LF norms or rules of use, rely solely on their L1 pragmatics and apply it to their LF. This may certainly unveil diverse underlying systems of values from those of other speakers (Olshtain and Cohen, 1989; Tran, 2006; Wierzbicka, 1996).

The literature also offers a plethora of examples of this type of pragmatic failure. For instance, Kakavá (1993) explains that different conversational styles were responsible for many misperceptions between Greeks, Greek Americans and Americans when facing arguments. She found that American professors took their Greek students' argumentation patterns as personal attacks or strong disagreement instead of as strong commitment to a position, so the professors regarded those students as 'opinionated', 'impolite' or 'too emotional'. In turn, Greek students perceived their American professors' mitigated disagreements as evasive and non-committal, which led them to think that their professors were 'detached' or 'dull'. Also, Chen (1993) shows that the Chinese tendency to reject compliments, motivated by the operation of the modesty maxim (Leech, 1983), created many misunderstandings when Chinese learners of English interacted with Americans, as the latter tended to accept compliments because of the operation of the agreement maxim (Leech, 1983) $)^{3}$. Finally, Jaworski (1995) illustrates that the sociocultural norms active in Polish

\footnotetext{
${ }^{2}$ Escandell Vidal (2004) explains that the terms 'norm' and 'rule' may have two senses. One is 'custom of use' or customary practices, i.e., '[...] internalised, unconscious patterns that the individual follows without even noticing that he is complying with an unwritten model' (Escandell Vidal, 2004, p. 349). The other sense is that of 'convention of use', or '[...] something external, socially imposed, that requires formal and explicit instruction' (Escandell Vidal, 2004, p. 349). This paper takes 'norms' to have both senses. Furthermore, following Escandell Vidal (2004), this paper opts for 'norms' and not 'principles' to refer to individuals' customs and conventions of use, as the latter term should be restricted to the '[...] formalised expression of the behaviour of a system', i.e., to a '[...] causal, mechanical explanation, a general law [...]' (Escandell Vidal, 2004, p. 349).

${ }^{3}$ Leech (1983) articulates his politeness principle on the basis of a series of maxims which complement those of Grice's (1975) cooperative principle. Among them are the modesty maxim -'(a) Minimize praise of self [(b)
} 
culture were responsible for Polish learners' offers of information and narrations about an object after receiving compliments on it.

From a relevance-theoretic perspective (Sperber and Wilson, 1986, 1995; Wilson and Sperber, 2002, 2004), it can be said that when both types of failure arise, hearers arrive at undesired or unwanted implicatures (Escandell Vidal, 1998), or alternative implicatures (Yus Ramos, 1999a, 1999b). In the failures presented above, users of an LF like English processed the formulae used for complimenting or responding to compliments, the phatic questions or the argumentative patterns of their interlocutors top-down (Kasper, 1984) and related them to scripts, make-sense frames (Yus Ramos, 2013) ${ }^{4}$ or cultural metarepresentations (Sperber, 1996) containing information about what is adequate or expectable in particular settings in their own culture. Since they faced formulae, questions or conversational styles that did not match the interactive patterns included in such knowledge structures, hearers derived that sort of implicatures and misunderstood their interlocutors' intentions (more on this below).

Individuals may react to pragmatic failures differently, depending on their degree of benevolence towards their interlocutors. Although they may find their interlocutors' communicative 'oddities' and mistakes simply funny or anecdotal, as in the case of the comparisons and metaphors used by Egyptian learners of English (Nelson, El Bakary and Al Batal, 1996), misunderstandings may also turn out to be puzzling or shocking (Beebe and Takahashi, 1989; Thomas, 1983, 1984). On other occasions, misunderstandings may induce hearers to make erroneous attributions of beliefs, PAs and personality traits, as in the case of the American professors and the Greek students (Kakavá, 1993), which may in turn lead to friction and communication breakdown. If individuals and communities of practice repeat and

\footnotetext{
Maximize dispraise of self]'- and the agreement maxim -'(a) Minimize disagreement between self and other [(b) Maximize agreement between self and other]' (Leech, 1983, p. 132; emphasis in the original).

${ }^{4}$ In an attempt at overcoming the overlapping between frequently used terms like 'frame', 'schema' and 'script', Yus Ramos (2013) coins the term make-sense frame in order to refer to encyclopaedic information related to specific terms (word-associated schemas), actions (sequence-associated scripts) and situations (situationassociated frames).
} 
perpetuate such attributions across time, negative stereotypes or labelling may originate and spread (Boxer, 2002; Fricker, 2007; Kasanga, 2001; Kasanga and Lwanga-Lumu, 2007).

One unfair attribution may be lack or deficit of communicative skills, as pragmatic failure could be thought to evidence a low level of pragmatic competence (Kasper, 1997) ${ }^{5}$ in the individual who commits them. Lack or deficit of communicative skills can be occasional, as in slips of the tongue, or more persistent, as in the case of L2 learners and LF users. As bilingual or multilingual individuals, these may not have achieved a thorough knowledge of and enough skills in the interlanguage they are developing. However, although ' $[\ldots]$ the yardstick by which the unstable bilingual [is] measured is the stable bilingual under social, cultural and historical conditions of language use, and with comparable goals for interaction in different discourse domains' (House and Kasper, 2000, p. 11), L2 learners and LF users must be regarded as multicompetent individuals (Cook, 1992, 1999). As such, they have developed a more complex, hybrid linguistic system in which both the L1 and the L2/LF are stored in the same brain areas, share the same conceptualiser and make use of the same cognitive mechanisms, like the inferential device or the mindreading module. Accordingly, L2 learners and LF users should not always be seen as deficient knowers or users of the language with which they communicate, but rather as individuals who have not internalised, and do not necessarily make use of, the same knowledge as other of its users or native speakers and may therefore take risks and make quite idiosyncratic linguistic innovations when interacting that should not be understood as real failures (Kecskes and Papp, 2000).

Nevertheless, understanding the negative outcomes of pragmatic failure requires answering why evaluations of real or seeming pragmatic failures arise in intercultural communication. This obviously requires an awareness of how individuals, as hearers,

\footnotetext{
${ }^{5}$ Pragmatic competence is here taken to refer to what Canale and Swain (1980) and Canale (1983) call sociolinguistic competence, to what Bachman (1990) labels pragmatic knowledge, or to both actional competence and sociocultural competence, as differentiated by Celce-Murcia et al. (1995). Nevertheless, it is a sub-component of the more general ability to use a language known as communicative competence.
} 
understand utterances, i.e., the heuristics they follow when processing utterances and the factors that lead them to reach a particular interpretation and evaluation of others' communicative behaviour. These issues are part and parcel of individuals' pragmatic competence and may have some impact on their performance as hearers. The next section addresses them from the relevance-theoretic perspective on communication (Sperber and Wilson, 1986, 1995; Wilson and Sperber, 2002, 2004).

\section{Relevance, Comprehension and Pragmatic Competence}

Being pragmatically competent in another language not only involves producing stretches of discourse suitable for the sociopragmatic context in which one has to interact, but also to understanding other individuals accurately (Bachman, 1991; Canale, 1983; Canale and Swain, 1980; Celce-Murcia et al., 1995). In spite of certain scepticism about whether communication and understanding can actually occur (cf. Taylor, 1992), individuals communicate and seem to understand each other to a greater or lesser extent. But communication is an incredibly risky activity amenable to misunderstandings where individuals accidentally arrive at undesired or unintended interpretations. For this reason, 'While providing extraordinary benefits, communication is also a source of vulnerability to accidental or intentional misinformation' (Mascaro and Sperber, 2009, p. 367).

A speaker intentionally produces an utterance because she has both an informative intention -the intention to make manifest a set of assumptions, i.e., to intentionally convey a specific message- and a communicative intention -the intention that another individual recognises that she actually intends to convey a message (Sperber and Wilson, 1986, 1995). For communication to succeed, the hearer must adequately process the utterance in order to arrive at the interpretation that the speaker intends to communicate. Utterance processing 
involves the joint work of decoding and inference in a series of tasks that include identification and segmentation of words, syntactic parsing, disambiguation of constituents, conceptual adjustment, reference assignment, identification of illocutionary force and of speech act, and recovery of implicit contents. These are carried out in an incredibly fast and apparently automatic way and require a certain amount of cognitive effort.

Utterances come with a tacit guarantee of their optimal relevance and generate firm expectations of relevance, i.e., expectations that processing them will be worth the cognitive effort that hearers will have to invest in those tasks because they will obtain some cognitive gain. That cognitive gain is cognitive effects, which can be the strengthening of old information, contradiction of old information -eventually leading to its rejection- or the derivation of new information from the interaction of old information with new information conveyed by the utterance. In other words, utterances create expectations that the cognitive gain that hearers will obtain from processing will compensate for the effort required. In fact, an utterance is accompanied by a presumption of its own optimal relevance, according to which the hearer is entitled to think that (i) the utterance is relevant enough for it to be worth his cognitive effort, and (ii) it '[...] is the most relevant one compatible with the communicator's abilities and preferences' (Sperber and Wilson, 1995, p. 270). Although there may always be information or ways to convey it - i.e., communicative strategies - which the hearer may consider more relevant, the speaker will normally do her best to choose what she thinks is the best means of achieving a particular communicative goal on the basis of her knowledge and communicative skills.

Upon drawing the hearer's attention, an utterance triggers a process in which the hearer constructs interpretive hypotheses and searches for plausible interpretations. But this is not a random process, as the hearer follows a cognitive heuristics that has been the result of centuries of evolution. It consists of following the interpretive path that provides the largest 
amount of cognitive effects and demands the least cognitive effort (Wilson, 1999; Wilson and Sperber, 2002, 2004). Once the hearer finds an interpretation that meets these two criteria, his expectations of relevance will be satisfied, so he may conclude that such interpretation is the one that the speaker intended to communicate and consider it to be the her informative intention. If the hearer does not find an optimally relevant interpretation, or if the interpretation that he reaches does not correspond to the one the speaker intended to communicate, communication will fail and misunderstandings will no doubt arise.

When following this heuristics, the simplest, and probably default, processing strategy with which the hearer searches for the intended interpretation is one in which he behaves as a naïvely optimistic individual (Sperber, 1994). As such, he presupposes two things:

a) that the speaker is benevolent, i.e., that she will not try to deceive him, and

b) that the speaker is (pragmatically) competent in the language she uses to interact, i.e., that she has an adequate command of its grammatical rules and pragmatic norms of usage, that she will try to avoid misunderstandings, and that she will guide him to intended interpretations through the path of least effort and maximum benefits (Mascaro and Sperber, 2009; Sperber, 1994; Sperber et al., 2010).

If the speaker is indeed benevolent and pragmatically competent, she will make sure (i) that the information she communicates will in fact turn out optimally relevant to the hearer, and (ii) that the formulation of her utterances -i.e., the lexical items she selects, the arrangement of its constituents, its formulaic elements, pronunciation and intonation, etc.- is appropriate so that the hearer quickly and easily accesses an appropriate context in which to process it and reaches the intended interpretation.

In most cases, speakers appear and are automatically supposed to behave both benevolently, as they do not seem to be willing to deceive their interlocutors, and competently in grammatical and pragmatic terms, as they are perceived to have a good command of a 
language and obey the cultural norms or conventions governing its usage. But, unfortunately, in many other cases, though still benevolent, speakers do not behave (fully) competently in pragmatic terms because they lack cultural knowledge regarding conventions and expected behaviour in specific circumstances or their expressive abilities are impaired by states such as absentmindedness, tiredness, nervousness, anxiety or drunkenness. Pragmatic incompetence can be occasional, as in the slips of the tongue, or more permanent, as in the case of L2 learners and LF users. These may lack the necessary inventory of formulae to accomplish some discourse functions, translate from their L1, resort to wrong suprasegmental features or deploy innovative and somewhat puzzling strategies to interact. Alternatively, although L2 learners and LF users are acquainted with the inventory of formulae frequently used to perform some acts, they may not have executive control over them and fail to know when, where and with whom to use them (Bialystok, 1993). Their pragmatic incompetence may surface when they commit pragmatic failures, which may be completely unintended and go unnoticed to themselves, but which may make their interlocutors interpret their communicative behaviour in quite unpredictable ways. So what are the effects of L2 learners and LF speakers' real or seeming pragmatic incompetence? And how may their interlocutors react when facing an authentic or apparent case of pragmatic incompetence?

The next Section argues that the human capacity to attribute beliefs, intentions and PAs to other individuals may induce hearers to ascribe to L2 learners and LF users some mental states that they do not actually have, among which the intention to communicate messages other than the intended ones. This is so because hearers, in an attempt to understand other people's behaviour, tend to interpret their behaviour in accordance with existing knowledge and internalised behavioural patterns considered adequate or expectable in particular contexts. As a consequence, infelicitous interpretations may accidentally achieve an optimal level of relevance and hearers may give them some credibility. 


\section{Pragmatic Incompetence and Mindreading}

When communicating in another language, individuals may experience phonological, morphological, lexical and syntactic deficits that may evidence inaccurate mastery of the language and prevent them from making manifest their informative intention in the most efficient way. They may also lack scripts, make-sense frames or cultural metarepresentations concerning interaction in specific communicative contexts, or the contents of those knowledge structures, which inform and determine their communicative behaviour, may slightly or significantly differ from those of other individuals. Additionally, they may not be aware of the constraints governing certain linguistic behaviours in specific circumstances within the target culture or language, which their interlocutors might expect them to abide by. Hence, speakers may unknowingly select behaviours or communicative strategies that turn out to be inappropriate and lead their interlocutors to assign an interpretation which differs, to a greater or lesser extent, from the one that speakers think those behaviours or strategies could have. Still, in other cases, speakers may not take into account some features of the situation in which they are interacting, which may favour one interpretation over another, or they may not foresee the contexts that their interlocutors will most directly and effortlessly access or construct in order to interpret utterances (Sperber, 1996, p. 192; Žegarac, 2009).

All these problems may provoke undesired pragmatic failures. Although individuals are benevolent and their behaviours and strategies may appear to themselves as perfectly valid and acceptable to the contexts where they interact, these may inadvertently diverge from their interlocutors' expectations or behavioural patterns. This may make their interlocutors read their minds erroneously and so attribute some beliefs and PAs that L2 speakers or LF users do not actually have or even some degree of occasional or permanent pragmatic incompetence or 
lack of social abilities.

According to Escandell Vidal (2004), individuals store in their social categorisation system a huge amount of information about interaction, which comprises relatively stable cultural metarepresentations about behaviour in specific contexts, recurrent means to achieve specific communicative goals, usual (default) meanings of some expressions or linguistic structures, etc. ${ }^{6}$ This system performs both a long- and a short-term tasks. The former consists of building up and updating its database of information regarding generalised, abstracted socially accepted behaviour. The latter, on the contrary, consists of analysing and categorising input, or in-coming information, on the basis of the database that the system possesses. This social categorisation system would be a domain-specific mechanism that is part of a more general inferential mechanism (e.g., Barkow et al., 1992). The analysis of input that it performs is an unconscious inferential process that occurs at the individual's brain at a subpersonal level, i.e., without the individual's actually deciding whether to perform it or not (Mercier and Sperber, 2011, p. 58). What the individual may nevertheless be aware of is the conclusions reached, so the inferences that this system performs are intuitive and generate intuitive beliefs, i.e., '[...] beliefs held without awareness of reasons to hold them' (Mercier and Sperber, 2011, p. 58) ${ }^{7}$.

When a speaker, on the grounds of her linguistic competence in the language with which she communicates and her preferences, selects a pragmalinguistic strategy or resorts to a particular behaviour for which the hearer's social categorisation system database has no information associated, or the information that it possesses does not exactly mirror that in the speaker's social categorisation system, the hearer's social categorisation system may fail to assign to them the interpretation that the speaker might have expected. On the contrary, the

\footnotetext{
${ }^{6}$ Following Jackendoff (1992), Escandell Vidal (2004, p. 358) postulates the existence of this system and depicts it as a mental '[...] component devoted to forming social representations [...] [and] sensitive to socially dependent features, such as power, distance, age, sex or degree of imposition, among others'.

${ }^{7}$ Intuitive beliefs differ from reflective ones in that the latter are '[...] held with awareness of one's reasons to hold them' (Mercier and Sperber, 2011, p. 58; see also Sperber, 1997; Sperber and Mercier, 2012).
} 
hearer's social categorisation system assigns to them an interpretation that is consistent or coherent with the information stored in its own database. The system would be affected by some sort of confirmation bias that prompts it to search for evidence and interpret it in accordance with existing beliefs and expectations (Nickerson, 1998, p. 175). In other words, the hearer's social categorisation system would look for information in its database in order to interpret pragmalinguistic strategies or linguistic behaviour and construct a hypothesis or some kind of argument that agrees with or backs previous information or expectations (Mercier and Sperber, 2011, pp. 63-64). In communication in English as an LF, this is what happens, for instance, with conventionally indirect requests formulated by means of pragmalinguistic structures such as the following ability questions:

(1) Can you do X? Could you do X?

For some learners and LF users of English whose native language is Slavic, those pragmalinguistic strategies are not proper requests, but genuine yes-no questions about their physical abilities. Accordingly, they may simply respond to them with an affirmative or negative answer, and may not capture the requestive force. Although their English interlocutors are fully competent in pragmatic terms, it is those learners or LF users that are not fully competent hearers from their perspective, as they fail to reach the intended requestinterpretation because of a different association between such formulae and their meaning in the database of their social categorisation system. Eventually, those learners or LF users might come to the conclusion that it was absurd of their interlocutor to ask such an obvious question or to more drastic conclusions regarding their personality, mood, intentions, beliefs, etc. Simplistic though this example may seem, it illustrates that individuals may wrongly interpret other individuals' pragmalinguistic and sociopragmatic choices and also incur a pragmatic failure if, as hearers, they do not infer their interlocutors' actual informative intention. Their social reasoning about others' linguistic behaviour may fail to evaluate and 
correct, if necessary, their own initial intuitive beliefs appropriately but find justifications for the resulting intuitive beliefs it may have constructed (Mercier and Sperber, 2011; Roberts and Newton, 2001; Sperber and Mercier, 2012). So how may L2 learners and LF users react when they notice a behaviour that does not match the information contained in the database of their social categorisation system or when facing what they might consider a case of pragmatic incompetence?

Individuals' occasional or permanent, real or supposed, pragmatic incompetence may have an impact on the interpretations that hearers reach, as these may draw undesired conclusions. Their relevance-driven social categorisation system analyses the in-coming input against its pool of specific knowledge (Escandell Vidal, 1996). If this system does not have representations to which it can associate such input, or the content of its representations differs from the content of the representations that determined the speakers' behaviour, two consequences follow.

On the one hand, the input produced by a seeming or real pragmatically incompetent speaker may achieve accidental relevance (Wilson, 1999) under another interpretation than the intended one. For instance, if an LF user belongs to a community of practice that assigns to compliments no value as solidarity-generating tokens, or does not perceive them to be expressions that suggest social proximity, concern for the complimentee, etc., he may perceive compliments in certain exchanges as flattering or insincere, among other possibilities. Thus, the LF user would derive alternative implicatures (Yus Ramos, 1999a, 1999b) that do not match the effects that his interlocutor might have expected compliments to produce. This is also what happens in the case of the pragmalinguistic and sociopragmatic failures described above (Chen, 1993; Han, 1992; Jaworski, 1995; Kakavá, 1993; Pavlidou, 1994, 1998).

On the other hand, the input produced by an incompetent LF speaker may achieve 
accidental irrelevance (Wilson, 1999) if the hearer cannot find in the database of his social categorisation system any assumptions linked to that input, so it does not yield any cognitive benefit that offsets the his effort. For instance, if an LF speaker does not know that small talk is not used by a target group in order to show a positive attitude towards other individuals or avoid the unpleasantness of silence (Laver, 1975; Padilla Cruz, 2004), her use of some small talk may have no social meaning for the hearers in that group and accidentally turn out irrelevant. Alternatively, input generated by an incompetent speaker may accidentally be irrelevant if the hearer knows the information that it makes manifest. For instance, a hearer may find a comment such as (2) to be irrelevant in a context in which he is late to some event, he knows the time and he is aware that he is late to that event:

(2) It is already 11.10 p.m.

Although the speaker's intention might have been to invite implicatures such as that the hearer should have arrived earlier or that she is annoyed at his being late, the speaker has not foreseen that assumptions about his delay could be highly salient to him. Hence, the hearer does not expand his context and fails to deduce the intended implicatures because he feels that the speaker only communicates known information. In this case, the communicative strategy that the LF speaker has selected reveals itself as inappropriate to guide the hearer to the intended implicit content, so she should have resorted to other linguistic formulation ${ }^{8}$.

Temporary or persistent incompetence may cause L2 learners and LF speakers to select ineffective strategies to make manifest their informative intention and attain specific communicative goals. With such strategies, they cannot avoid inadvertently communicating undesired messages and leading their interlocutors to incorrect conclusions. In an attempt at making sense out of strategies or behaviour that appear 'strange' or 'weird' to hearers, these make hypotheses about the speakers' intentions -not only desires and wishes, but also their

\footnotetext{
${ }^{8}$ Padilla Cruz (2012a, 2013a, 2013b) shows other frequent interpretive mistakes, made by learners or arising in intercultural communication, at both the explicit and implicit level of communication.
} 
informative intention- and PAs on the grounds of both the linguistic evidence presented to them -i.e., utterances- and their own knowledge structures. If such interpretive hypotheses accidentally achieve optimal relevance, hearers may believe the conclusions they arrive at to be the intended ones without wondering whether their interlocutors might not have meant them. To put it differently, relying on the speakers' communicative behaviour as well as the interpretations hearers arrive at, the latter may attribute some prefailure beliefs and PAs to speakers (Field, 2007). These would have allegedly informed, motivated and prompted the speakers' behaviour, but speakers may not actually hold, entertain, experience or even endorse them. Indeed, as Mercier and Sperber comment, '[...] people sometimes look for reasons to justify an opinion they are eager to uphold' (2011, p. 66), that opinion being in this case a conclusion they reach and that reason the other individual's prefailure beliefs and PAs. Thus, they do not revise the beliefs in the database of their social categorisation system. The calamitous consequence is that hearers feel induced to think that their interlocutors are dull, detached, opinionated, impolite or rude, may want to cause offence, be nosy and invade their personal sphere, challenge a certain social relation, unduly impose upon them or provoke an interactive conflict, as in the examples of pragmatic failure discussed above. On the basis of the speakers' infelicitous behaviours and linguistic choices, hearers cannot refrain from erroneously read their minds (Field, 2007).

The constant search for the optimal relevance of stimuli and mindreading abilities may lead hearers to attribute certain underlying beliefs and PAs to real pragmatically-incompetent speakers or to individuals who are supposed to behave incompetently. Hearers either select inadequate contextual assumptions for processing their communicative behaviour or detect a mismatch between those individuals' linguistic behaviour and their own cultural metarepresentations dictating what is adequate or expectable in particular contexts. Cultural metarepresentations encourage hearers to anticipate the way in which other individuals could 
or should behave, or to expect certain outcomes from their behaviour in given situations (Sperber, 1996). Many of such representations are stable and remain unquestioned or unchallenged because individuals find them relevant to themselves or uncontroversial among the members of the milieu they interact with (Mercier and Sperber, 2011, p. 66). When L2 learners and LF users' actual communicative behaviour does not meet hearers' expectations, these may attribute unwarranted beliefs and PAs to them in an attempt to find reasons for their behaviour. In turn, erroneous mindreading may result in puzzlement, surprise, shock, frustration, disappointment or anger, although this will evidently depend on the hearers' degree of benevolence towards their interlocutors. But what may happen if hearers experience such reactions? Could those reactions have other more serious consequences for interaction?

What follows suggests that if speakers are not understood correctly and are erroneously thought to have certain beliefs or intentions that motivate their actions because of their real or apparent performance mistakes, hearers may experience a negative bias against them and wrong them in their capacity as communicators. Hence, hearers may sustain a particular type of injustice against them, question their communicative abilities and degrade them as communicators.

\section{Mindreading and Epistemic Injustice}

Communicative behaviour that a hearer perceives as 'weird', 'strange' or 'deviant' may accidentally and inadvertently lead him to an unfortunate, unintended interpretation. If the hearer cannot relate a speaker's communicative behaviour to contextual assumptions or information in his social categorisation system, he may perceive it as incongruent, contradictory or meaningless and expand his interpretive context in search for reasons for it, as people are supposed to act guided by motives and individuals may be interested in knowing 
or figure them out (Sperber and Baumard, 2012, pp. 503-505). This process is effortdemanding, so the hearer feels entitled to expect some cognitive reward -i.e., cognitive effects- which offsets that effort (Sperber and Wilson, 1986, 1995). In an attempt to make sense out of the speaker's behaviour, the hearer will attribute beliefs and PAs to the speaker, which he believes to have informed and motivated the speaker's actions (Field, 2007, p. 134; Mercier and Sperber, 2011, p. 66). However, such attribution may be ill-founded or unwarranted, as the speaker's actions might not have been '[...] guided by occurrent [actual] beliefs [and PAs]' (Field, 2007, p. 133) which the hearer thinks. In effect, in many troublesome situations where misunderstanding arises it is not the speaker's intention to be offensive, rude, impolite, dull, opinionated, bossy, etc., but the hearer finds in her behaviour supportive evidence to come to such conclusions (Mercier and Sperber, 2011; Sperber and Mercier, 2012). Thus, an interpretation that should not have otherwise achieved an optimal level of relevance accidentally and unintentionally appeals the hearer as optimally relevant and the hearer accepts it as the intended one. As a result of coming to an erroneous conclusion, the hearer ends up forging an inadequate and unfair perception of his interlocutor.

Ill-founded or unwarranted attributions of beliefs and PAs to speakers who occasionally or permanently make pragmatic mistakes, or whom hearers suppose to be incompetent because of their pragmatic performance, may lead hearers to wrong those speakers, specifically in their capacity as knowers and users of an L2/LF. Following Fricker (1998, 2003, 2006, 2007), when hearers perceive their interlocutors as less competent than desired and wrong them, those speakers may be the target of an epistemic injustice as knowers and users of the language wherewith they communicate ${ }^{9}$. The term 'epistemic injustice' covers, on the one hand, a specific type of harmful, wrongful, unfair and negative bias, as a result of which individuals do wrong to others on the grounds of the alleged quality of their testimony. This is

\footnotetext{
${ }^{9}$ Coady (2010) contrasts Fricker's (2003, 2006, 2007) notion of epistemic injustice to that of Goldman (1999), for whom the term refers to an unfairness in the distribution of knowledge as an epistemic good.
} 
testimonial injustice, the unfairness individuals may sustain against others when they feel that the information that those individuals dispense should not be credited because of its falsity or scarce reliability (Fricker, 2007). Testimonial injustice arises when an individual receives or is assigned less credibility than she deserves from another individual because the latter has a certain prejudice against her (Fricker, 2003, p. 154). As a consequence, that individual disbelieves what the speaker tells him, even if the she deserves to be believed, or lowers his degree of belief in the speaker.

On the other hand, the term includes another category of unfairness: hermeneutical injustice, '[...] the injustice of having some significant area of one's social experience obscured from collective understanding owing to persistent and wide-ranging hermeneutical marginalisation' or to '[...] a structural prejudice in the collective hermeneutical resource' (Fricker, 2006, p. 99). When an individual suffers a hermeneutical injustice, her credibility is not at issue, but her intelligibility. Hermeneutical injustice occurs when an individual is not understood to the extent that she deserves or as she would have expected to be understood (Fricker, 2006, pp. 105-107, 2007, p. 151). In other words, individuals may suffer this subtype of epistemic injustice if there is '[...] a collective hermeneutical lacuna [...] preventing [them] from rendering [their] experience communicatively intelligible' (Fricker, 2006, p. 101). Hermeneutical injustices may be systematic -i.e., persistent- or incidental, as they may involve fleeting or more persistent negative biases against whom the injustice is inflicted. Incidental hermeneutical injustices ' $[\ldots]$ stem not from any structural inequality of power but rather from a more one-off moment of powerlessness' (Fricker, 2006, p. 100). Regardless of whether a hermeneutical injustice is systematic or incidental, '[...] it involves no perpetrator, no culprit' (Fricker, 2006, p. 102) because it is a form of social inequality as a result of which a person may be marginalised. The individual who suffers this injustice is marginalised or discriminated because of his inability '[...] to make communicatively intelligible something 
which it is particularly in his interest to be able to render intelligible' (Fricker, 2006, p. 103) ${ }^{10}$.

When an L2 learner or LF user commits a pragmatic failure, her knowledge of the world or of specific matters, as well as her ability to give testimony and the quality thereof, are not at stake. Rather, it is her knowledge of and competence in the language with which she interacts -in other words, her knowledge of its conventions of meaning and usage, as well as her abilities and skills as a communicator- which are indeed at stake and prevent her to be correctly understood. If pragmatic failures arise and hearers wrong speakers by attributing non-occurrent beliefs and PAs, hearers are wronging them as regards their communicative skills and linguistic or pragmatic knowledge. Since an individual may suffer a hermeneutical injustice when her intelligibility is at issue, Fricker's (2006, 2007) notion of hermeneutical injustice could be loosened or expanded in order to subsume those cases in which individuals are not understood as they might have expected or intended, i.e., those cases in which their communicative behaviour fails to achieve the expected or intended communicative goals (cfr. Coady, 2010). Accordingly, instead of using the general term 'hermeneutical injustice' to portray a wronging resulting from perceptions of real or apparent communicative incompetence, such wronging could be labelled linguistic-hermeneutical injustice or, more precisely, pragmatic-hermeneutical injustice. This modification highlights that the unfairness referred to stems from a wronging that a hearer does on the basis of a communicative behaviour that he perceives as a 'strange', 'incongruous' or 'contradictory' and may, but needs not, be caused by the speaker's deficient or incomplete pragmatic knowledge of the L2/LF, her defective communicative skills, an attempt at communicating as clearly and effectively as possible through the linguistic resources available or a puzzling linguistic innovation in the interlanguage (Cook, 1992, 1999; House and Kasper, 2000; Kecskes and

\footnotetext{
${ }^{10}$ Individuals may be hermeneutically marginalised or disadvantaged when '[...] there is unequal participation with respect to some significant area(s) of social experience [...]' (Fricker 2006, p. 99), i.e., when they lack concepts that enable them to conceptualise and talk about certain domains of their identity, conditions affecting them or experiences they may be involved in.
} 
Papp, 2000). As opposed to Fricker's (2006, 2007) view of hermeneutical injustice, pragmatic-hermeneutical injustice has a perpetrator: the hearer who misunderstands the speaker as a consequence of her real or seeming pragmatic incompetence (more on the need of this coinage below).

Individuals may sustain a pragmatic-hermeneutical injustice if, and only if, they receive a pragmatic competence deficit because of their real or apparent performance mistakes (cf. Fricker, 2007, p. 28). To put it differently, L2 learners and LF speakers may be the target of this new sub-type of hermeneutical injustice when other interlocutors think that their pragmatic competence -or even more generally, their communicative competence- is deficient or not as developed as desirable or expectable. In fact, the capacity to use a language efficiently -and, for the purposes of this paper, an L2/LF- in order to interact with other individuals is, as Fricker (2007, p. 44) aptly points out, '[...] one side of that many-sided capacity so significant in human beings: namely, the capacity for reason'. When someone gives signs of not being fully (pragmatically) competent in an L2/LF, or when a hearer supposes that person not to be fully competent, that person may be believed not to reason adequately as regards communicative behaviour appropriate to specific interactive contexts. Indeed, many L2 learners and LF speakers fail to discern the best possible linguistic means to achieve certain communicative goals and/or unknowingly choose strategies that turn out inadequate to their own and their interlocutors' relative power, the social distance mediating between them and their respective sociality rights and obligations (Brown and Levinson, 1987; Spencer-Oatey, 2000). Pragmatic-hermeneutical injustices may, but need not, be confined to a single moment of interaction or to a single conversational exchange. As with epistemic injustices in general, which '[...] are created and maintained through a sustained effort over time and across generations [...]' (Medina, 2011, p. 17), pragmatic-hermeneutical injustices require that the individual who sustains them does so repeatedly, i.e., in different 
exchanges or at different moments in the same exchange, as he must arrive at negative conclusions about the other interlocutor's behaviour, which may subsequently have a negative impact on his perception of that person.

When someone suffers an epistemic injustice, that individual is degraded as knower and denied or deprived of epistemic trustworthiness (Fricker, 2007). In turn, hermeneutical injustice may bring about a loss of epistemic confidence in the individual who experiences it i.e., a loss of certainty in his beliefs- which may '[...] inhibit the development of intellectual courage, the virtue of not backing down in one's convictions too quickly in response to challenge' (Fricker, 2006, p. 104). Quite similarly, when someone suffers a pragmatichermeneutical injustice because of their unusual or strange communicative behaviour and/or defective pragmatic skills, that individual may be degraded as competent speaker of an L2/LF and denied or deprived of what can be called -in an analogous way to Fricker $(2006,2007)$ communicative or pragmatic reliability. Communicative or pragmatic reliability requires the concurrence of both sincerity -or, in Sperber's (1994) terms, benevolence- and competence in the linguistic system used -i.e., communicative competence. These two factors are, following Medina (2011, p. 18), comparative and contrastive in nature: an individual can be judged as sincere or credible to some extent and as more or less competent with respect to others. Furthermore, being communicatively competent in an L2/LF is not an all-or-nothing matter, but a gradable and context-bound characteristic: an individual may be more communicatively competent in some interactive situations, but not in others, and thus be more or less successful at achieving some communicative goals. When someone sustains a pragmatic-hermeneutical injustice against an L2/LF speaker as a result of ill-founded or unwarranted attributions of beliefs and PAs, and so that person wrongs the L2/LF speaker, he may be attacking one of the components of that speaker's communicative or pragmatic reliability: their competence. In other words, that person may be implicitly suggesting that the speaker in question may not be 
a reliable communicator, not because of the credibility of the knowledge she dispenses, but because she is unable to make manifest in the most efficient and least effort-demanding way their informative intention, i.e., the speaker fails to get across her messages, make the hearer identify her interactive goal(s) in the most effective and effortless way or be understood as he deserves and/or expects. This could be enough for being wronged in terms of communicative competence.

Epistemic injustices are ultimately the root of negative stereotypes related to individuals' capacities as knowers and the quality of the knowledge they possess and dispense (Fricker, 2007). Although not as dangerous as such injustices, pragmatic-hermeneutical injustices may be somewhat troublesome because of a greater or lesser denial or deprivation of communicative or pragmatic reliability. They may also have a negative impact on a crucial aspect of human sociality and culture individuals are concerned about: their reputation, '[...] a socially transmitted, typically evaluative judgement that is presented as consensual, or at least as widely shared' (Sperber and Baumard, 2012, p. 509), or, as Origgi (2013, p. 231) portrays it, '[...] the social information our patterns of actions leave around [...] the set of social evaluative beliefs that have been cumulated around a person [...]'. When an individual notices that another is not an efficient or skilled communicator, the former may consistently doubt about the latter's subsequent ability to convey information in a precise, clear and unambiguous way (à la Grice, 1975) or to select communicative behaviours that fit the social contexts in which they interact and respect their sociality rights and obligations (Brown and Levinson, 1987; Spencer-Oatey, 2000). This wronging may negatively condition perceptions of L2 learners and LF users and challenge or threaten their reputation. As Sperber and Baumard (2012, p. 511) explain, managing one's own reputation requires the ability '[...] to anticipate the reactions of others to one's own actions and attitudes, including their reactions to our reactions, to the actions of third parties, and so on'. If an individual ends up sustaining 
a pragmatic-hermeneutical injustice against an L2/LF speaker as a result of pragmatic failure, such failure prevents the L2/LF speaker from managing her reputation appropriately, as she fails to predict the consequences that her linguistic behaviour may eventually have. In this scenario, a hearer who misunderstands an L2/LF speaker and does a pragmatic-hermeneutical injustice may be socially constituting the speaker as, or even causing her to be, '[...] something [the L2/LF speaker is] not, and which it is against [her] interest to be seen to be' (Fricker, 2006, p. 107). And once an individual has formed a picture of or an attitude towards another, he will tend to search for additional evidence backing such picture or image in such a way, that the individual's social reasoning will become more biased and the individual will feel a certain pressure to justify that picture or attitude, even if wrong, rather than abandoning them (Mercier and Sperber, 2011, p. 67) ${ }^{11}$.

To sum up, while epistemic injustice undermines the individual's reputation as knower and hermeneutical injustice undermines the individual in her capacity as interpreter of experiences, pragmatic-hermeneutical injustice would undermine the individual in her abilities as a communicator and in her capacity to communicate in the most effective manner. If uncorrected and continued across time, pragmatic-hermeneutical injustice may even progressively erode social relationships: individuals may refuse to recruit or select individuals who actually are or appear to be pragmatically incompetent for future cooperative communicative interactions (cfr. Baumard et al., 2013). If this may be so, how could pragmatic-hermeneutical injustices be avoided or overcome?

The following Section argues that hearers may avoid or overcome this type of injustice if they adopt a critical attitude towards the interpretations they arrive at. Such attitude enables hearers to move from a position of automatic gullibility or indiscriminate trust that makes them accept their own interpretations unquestioningly to a more sceptical one.

\footnotetext{
11 This need to find additional supportive evidence contributing to the anchoring of one's conclusions or perceptions is known as bolstering (McGuire, 1964; quoted in Mercier and Sperber, 2011, p. 67).
} 


\section{Avoiding Pragmatic-hermeneutical Injustice}

What happens in many pragmatic failures seems clear. If one considers the speaker's role in communication, (seemingly) inappropriate communicative behaviours accidentally achieve an optimal level of relevance under an interpretation that the speaker might not have foreseen. On the basis of her abilities and preferences as a communicator (Sperber and Wilson, 1995, p. 270), the speaker selects what she thinks is an optimally relevant stimulus to achieve a communicative goal, but temporary or permanent incompetence because of unawareness of L2/LF conventions of use, lack of knowledge about more appropriate pragmalinguistic strategies or failure at predicting assumptions manifest to the hearer prevents the speaker from producing the utterance that will achieve her communicative goal and actually be most relevant. Focusing on the hearer's role, many pragmatic failures can be said to originate also because the hearer behaves as a naïvely optimistic individual: he accepts the first interpretation that satisfies his expectations of relevance, believe it to be his interlocutor's informative intention without questioning it and makes ill-founded or unwarranted attributions of beliefs and PAs. These attributions may eventually give rise to pragmatichermeneutical injustices and contribute to degrade the speaker as a knower and user of an L2/LF.

Hearers sometimes make such unfortunate attributions because they do not adopt a critical stance to the communicative behaviour that they perceive -i.e., to the information that the speaker communicates and the strategies she selects in order to achieve a particular communicative goal- to the contextual or cultural information against which they process that behaviour and to the very conclusions they derive. Individuals have epistemic trust, an attitude that Origgi (2013, p. 224) characterises as comprising two components: 
a) Default trust, or the minimal trust allocated to interlocutors and necessary for the success of communication.

b) Vigilant trust, which is '[...] the complex of cognitive mechanisms, emotional dispositions, inherited norms, reputational cues [...] put at work while filtering [...] information'. Some of such cognitive mechanisms could be directed to interpretations. Not adopting such critical stance may lead hearers to unquestioningly give credit to those conclusions and believe them. Our cognitive mechanisms have developed some sort of critical alertness to our information sources: to the individuals with whom we interact, the information they dispense and the information that we make use of in order to process what they communicate. Such alertness is epistemic vigilance (Mascaro and Sperber, 2009; Sperber et al., 2010) and it can be described as '[...] a critical stance towards the communicated information' (Sperber et al., 2010, p. 363). It resides in a series of mechanisms whose domain of operation is communication, where it checks both the credibility and reliability of our interlocutors and information per se. Epistemic vigilance is not simply the opposite of trust; neither is it some kind of default or automatic distrust. Epistemic vigilance is the opposite of blind, uncritical and naïve trust in others as dispensers of information as well as in the testimony they give (Mercier and Sperber, 2011; Sperber and Mercier, 2012; Sperber et al., 2010). As Sperber (2013, p. 64) notes, it is a kind of monitoring towards the possible risk of deception that cannot be confused with some sort of distrustful 'paranoid attitude'. Although it plays a crucial role, whether individuals allocate trust to others also depends on factors such as previous judgements, social perceptions, commitments and heuristics that '[...] [they] rarely take the time to unpack when [they] face the decision to accept or reject a piece of information' (Origgi, 2013, p. 223) ${ }^{12}$.

\footnotetext{
12 There are, nevertheless, some doubts as to the indispensability and adaptiveness of epistemic vigilance, as well as to the frequency with which individuals are vigilant based on children and adults' ability to detect deception and attribute trustworthiness to others on the basis of factors such as consensus, age of informants, gestures or nervousness (Michaelian, 2013, pp. 38-43). Research by Levine and colleagues (Levine et al., 1999; Levine et
} 
Epistemic vigilance plays a crucial role in argumentation, where it checks the validity, strength, coherence and consistence of premises (Mercier and Sperber, 2011; Oswald, 2011). It also seems essential in humour, above all in some types of jokes in which the humourist favours an interpretation that easily appeals the audience as optimally relevant, but which the audience must reject in favour of another equally plausible interpretation they have to work out (Padilla Cruz, 2012b). But some form of vigilance also seems fundamental to overcome different types of misunderstanding at the explicit and implicit level of communication, in which hearers arrive at erroneous interpretations that accidentally achieve optimal relevance and believe them to be the intended interpretations (Padilla Cruz, 2013a, 2013b). Therefore, it could be reasonable to assume that vigilance could also be exercised towards other problems and risks germane to communication, such as the fact that another individual is not, or does not appear to behave as, a fully pragmatically competent speaker. To be precise, epistemic vigilance may also target those unusual, 'strange' or deviating communicative behaviours that induce hearers to wrong and ascribe a lack of competence to L2 learners and LF users and, eventually, to sustain a pragmatic-hermeneutical injustice against them. Although Sperber et al. (2010) describe epistemic vigilance as a suite of mechanisms monitoring against deception in order to test the credibility of informants and the testimony they give as a previous stage to the formation and fixation of beliefs, some kind of vigilance could also be exercised towards the interpretations hearers arrive at, on which subsequent beliefs may be highly contingent (Padilla Cruz, 2013a, 2013b). This vigilance could be referred to as hermeneutical vigilance and would be integrated in the architecture of mechanisms of epistemic vigilance (more on this below).

Some epistemic injustices could be said to originate because hearers do not behave as highly vigilant individuals or their vigilance has a lower degree of activation. In other words,

al., 2006; Levine, 2010; Levine and Kim, 2010; Levine et al., 2010) shows that there are situations in which people tend to believe others, so they would not need to be constantly vigilant against deception (more on this below). 
their hermeneutical vigilance may not be fully operative or work properly at times, so it can be overcome by the relative straightforwardness and effortlessness of the conclusions they arrive at. Michaelian (2013, p. 42) considers that the mechanisms of epistemic vigilance may not always be effective, so he distinguishes three types of vigilance:

(i) Strongly effective vigilance: individuals exercise bare vigilance and usually avoid being deceived.

(ii) Moderately effective vigilance: individuals exercise bare vigilance and usually avoid deception, but thanks to the joint contribution of both vigilance and some other factor.

(iii) Weakly effective vigilance: individuals exercise bare vigilance but it does not suffice and so they avoid deception thanks to some other factor.

He is inclined to think that vigilance is normally weakly effective because individuals have developed some sensitivity to a wide array of cues for deception and '[...] some good-enough method of approximating highly accurate situation-by-situation evaluation of trustworthiness' (Michaelian, 2013, p. 46). Indeed, research has shown that people normally tend to be truthbiased in face-to-face interaction when they are well acquainted with their interlocutors and do not suspect them to be deceitful as a result of taking into account a variety of clues for deception (Levine et al., 1999; Levine et al., 2006; Levine, 2010; Levine and Kim, 2010; Levine et al., 2010). In these cases, individuals would not need to be constantly vigilant. Sperber (2013, p. 64), however, concedes that vigilance may be moderately effective. Likewise, Origgi (2013, p. 224) claims that individuals may sometimes raise their vigilance '[...] by a closer inspection of data, sometimes by interrogating [themselves] about the sources of [their] trust or mistrust, and sometimes by refining [their] cognitive heuristics'. If individuals raise their vigilance, they are, in her words, actively vigilant, so they may become aware of the heuristics they exploit to process information and the biases that might have affected their processing. According to Origgi (2013, pp. 226-227), active vigilance involves: 
a) External vigilance. The individual tries to become aware of the cultural norms he and others abide by and the contextual information against which he processes input. Then, the individual separates the valid heuristics from those that may have been influenced by biases, internalised norms, emotional reactions or moral commitments.

b) Internal vigilance. The individual distances himself from the conclusions he might arrive at and makes an effort to trace their origin and consequences. Therefore, the individual adopts a vigilant attitude towards the interpretive steps taken, the beliefs he makes use of when contextualising information and conclusions reached in order to maintain a critical stance on the reasons, biases, social pressures and/or prejudices that might affect his way of thinking. This is hermeneutical vigilance.

When individuals adopt an actively vigilant attitude, they monitor different sources that determine the trust they allocate to their interlocutor. Adapting Origgi's (2013, pp. 227-233) sources of trust, it could be reasonable to assume that, in intercultural contexts where an L2/LF is used, a hearer who adopts an actively vigilant attitude will monitor the following sources of communicative reliability, which may cause him to think of the speaker in a particular way or another:

(i) Obvious signs of the speaker's reliability, such as not being a native speaker or insufficient mastery of the L2/LF, as well as previous beliefs and prejudices that the hearer might have accrued from previous exchanges and might have an impact on the epistemic injustice he sustains against the speaker.

(ii) Inferences on what the speaker says, i.e., on the appropriateness of the communicative strategy selected to convey some message or achieve some communicative goal, as well as the relevance of the information she communicates.

(iii) Internalised social norms of complying to authority, e.g., if the speaker exerts expert or referent power (Thomas, 1995) over the hearer, or vice versa, and so the hearer may 
come to some conclusions influencing his perception of the speaker's personality, and the extent to which the speaker's behaviour conforms to the social norms the hearer abides by or expects to be respected.

(iv) Socially distributed reputational cues about the speaker's reliability as a communicator in the $\mathrm{L} 2 / \mathrm{LF}$.

(v) Robust signals that may unveil lack of mastery of or handicaps in the L2/LF, such as frequent rephrasing, difficulties at finding adequate words, foreign pronunciation and intonation, odd syntax, stuttering or hesitation.

(vi) Emotional reactions that may affect the conclusions derived about the speaker.

(vii)Moral commitments determining whether the hearer should actually think of the speaker in a particular way or another.

If hearers were actively vigilant or exercised strong hermeneutical vigilance, they would not uncritically accept the conclusions they derive from a pragmatic failure. Rather, they would question the validity of speakers' linguistic choices to fulfil specific informative intentions and the accuracy of those conclusions they are led to derive and then wonder if the speakers might have intended to communicate something different from what they take speakers to communicate and in a different manner -i.e., by means of another communicative strategy.

The suite of mechanisms of epistemic vigilance could also include some kind of caution towards the interpretations that individuals may reach. This caution becomes essential not only in intercultural contexts where interlocutors are not fully competent in a language, are unaware of its sociopragmatic norms or behave guided by their L1 sociopragmatic norms, but also in any situation where speakers experience a temporary lack of pragmatic abilities due to factors like absentmindedness, anxiety, nervousness, drunkenness, etc., which may have an impact on their linguistic choices. Exercising active vigilance would contribute to the avoidance of pragmatic-hermeneutical injustices thanks to a monitoring of the interpretive 
steps taken in order to arrive at a particular interpretation, as well as the contextual or cultural information exploited: hermeneutical vigilance would check the reliability and suitability of such information for processing a particular communicative behaviour and the feasibility of interpretive hypotheses constructed on the basis of expectations of optimal relevance (Padilla Cruz, 2013a, 2013b).

Individuals usually adopt a default trustful attitude towards information and their interlocutors and '[...] trust their vigilance', as Origgi (2013, p. 224) puts it, so they do not permanently check if epistemic vigilance fulfils its functions adequately. The result is that they may be right or wrong when making some deductions and fixing specific beliefs. Apparently, individuals check if their epistemic vigilance may have worked properly '[...] when the stakes are high' (Origgi, 2013, p. 224). When pragmatic failures arise and hearers misunderstand their interlocutors, hearers might have taken their interlocutors' benevolence and competence for granted beforehand and so they do not realise that their linguistic choices are troublesome. Assuming that speakers are both benevolent and competent may not duly activate hearers' epistemic vigilance or even lower its level of activation and make hearers accept seemingly optimally relevant conclusions without questioning them.

Epistemic vigilance must involve a certain capacity to internally test whether the interpretations arrived at can be credited to be the intended ones. Naïvely optimistic hearers follow the relevance-theoretic comprehension procedure and stop processing upon reaching one interpretation that satisfies their expectations of relevance. Even if that interpretation is not the intended one, they may believe it unquestioningly. Hearers thus adopt what Clément et al. (2004, p. 361) call a position of indiscriminate trust. Naïve optimism may underlie hearers' attributions of wrong beliefs and PAs, so it may not always be the best possible interpretive strategy to deal with cases of real or seeming pragmatic incompetence and, therefore, to avoid or overcome pragmatic-hermeneutical injustices. Hearers must be able to 
switch to another processing strategy that involves a greater degree of sophistication. This switch would be triggered by epistemic vigilance thanks to an exploration of the different sources of communicative reliability and the realisation that something might have gone wrong: vigilance would alert to the speaker's insufficient competence or inadequate performance, unreliability of premises used in inferential processes or implausibility of interpretive hypotheses (Padilla Cruz, 2012b, 2013a, 2013b).

A more sophisticated processing strategy would enable hearers to reject accidentally relevant or irrelevant interpretations and consider alternative ones that do not induce them to think that their interlocutors' beliefs and PAs differ from their actual ones. This strategy is cautious optimism, defined by Sperber as '[...] a special case of competent attribution of intentions' (1994, p. 192). Following Clément et al. (2004, p. 362), cautious optimism could be said to provoke a position of sceptical trust ${ }^{13}$. A cautiously optimistic hearer is able to detect that the interpretation he arrives at and is led to accept on the basis of the speaker's behaviour, the information she communicates and the way in which she phrases it may not actually be the intended interpretation. Consequently, he may be willing to undertake additional cognitive effort and expand his interpretive context by accessing different contextual sources in order to search for another interpretation. To put it differently, epistemic vigilance would arouse some suspicion in the hearer which prompts him to wonder which other interpretation the speaker might have aimed to communicate and expected him to arrive at. Thus, a cautiously optimistic hearer can preserve the assumption that his interlocutor is benevolent, and so does not have certain hidden intentions or want to project some feelings or

\footnotetext{
${ }^{13}$ Clément et al. (2004, pp. 361-363) call indiscriminate trust a position of trust towards testimony, as a result of which some belief states are induced and the individual believes them to be true. They distinguish it from sceptical trust, which is a position in which an individual does not straightforwardly and uncritically trust the information provided by another person who has proved unreliable beforehand, and from gullible trust, a position in which individuals adopt testimony from other individuals even if it contradicts previous personal observations. In the case of communication, and more specifically, communication between people who use make use of an L2/LF that they do not adequately master, indiscriminate trust would consist of a blind acceptance of the interpretations they arrive at without even doubting whether they might have made some interpretive mistake. In contrast, sceptical trust would refer to the position in which the hearer suspects that the interpretation he considers might not be the best one.
} 
attitudes towards him, although he must discard the assumption that his interlocutor is competent in pragmatic terms or always behaves competently. Moreover, epistemic vigilance would predispose individuals to be alert to further incoming stretches of discourse and future conversational encounters in order not to blindly accept the interpretations they might come up with, but, so to say, to take them with a pinch of salt and question what they think speakers could supposedly have meant.

Many undesired pragmatic failures and pragmatic-hermeneutical injustices could be said to arise as a consequence of hearers not behaving as cautiously optimistic individuals and not adopting a position of sceptical trust. In order to overcome such injustices, hearers must switch to cautious optimism so as to attribute to their interlocutors the intention to communicate different interpretations from those that they initially reach and may be tempted to believe as a consequence of their accidental relevance. Accidentally relevant interpretations incite hearers to wonder about the reasons why their interlocutors behave in a(n apparently) unusual, 'strange' or deviant way and, consequently, to attribute non-occurrent beliefs and PAs to their interlocutors. Hearers must consider other interpretations as the most relevant ones upon realising that their interlocutors may suffer a temporary pragmatic incompetence or they interact with speakers who have an inaccurate or insufficient command of a language, misinformed linguistic preferences or reduced cognitive abilities, or simply obey different interactive norms at specific moments. Cautious optimism is necessary because speakers do not often think of better formulations for their utterances or behave in ways which prevent their interlocutors from obtaining, with minimal effort, the expected cognitive effects. Cautious optimism is also required because many speakers do not often notice contextual factors that favour alternative interpretations instead of those they seek to communicate or because they are unable to foresee the context against which their hearers will interpret their behaviour. In fact, hearers may accept some infelicitous interpretations as intended as a 
consequence of processing them on the grounds of the information stored in the database of their own social categorisation system. Moreover, cautious optimism is indispensable because hearers must be aware that the way they perceive and interpret communicative behaviour needs not be the most appropriate so, even though the speaker performs poorly, they may also fail to arrive at the most adequate interpretation. Thanks to cautious optimism a hearer can overcome a meta-blindness -i.e., '[...] a particularly recalcitrant kind of ignorance about the cognitive and affective limitations of one's perspective' (Medina, 2011, p. 29)- which would be the ultimate factor leading to the pragmatic-hermeneutical injustices that a hearer may sustain against a speaker. Following Medina (2011, pp. 29-30), cautious optimism would make it possible for the hearer to seek some kind of epistemic, interpretive or hermeneutical friction that would avoid a pragmatic-hermeneutical injustice by searching for alternative interpretive possibilities, considering if what he thinks about the speaker is right or unfair, establishing comparisons and contrasts between the speaker's communicative behaviour just perceived and assessed and previous instances of her behaviour (if that was possible) and looking at her actual behaviour from various angles.

\section{Conclusion}

This paper has focused on the consequences that pragmatic failures might have on hearers. It has described how hearers, on the grounds of strange or deviant communicative behaviour and their respective pool of knowledge may misconstrue their interlocutors and sustain pragmatic-hermeneutical injustices. If spread throughout a group of individuals in the fashion cultural metarepresentations spread and if perpetuated (Sperber, 1996), these would be the basis of inaccurate stereotypes and unfair prejudices (Fricker, 2007). Readers might still wonder if a term like 'pragmatic-hermeneutical injustice' is really necessary at this stage and 
why. Note that the term 'pragmatic failure', as well as the others used to label its subtypes, is mainly employed in the literature as if speakers were solely responsible for it, for pragmatic failures are more noticeable from their performance mistakes. However, hearers may also be held responsible for some pragmatic failures owing to the interpretive mistakes they may make (Padilla Cruz, 2012a, 2013a, 2013b; Yus Ramos, 1999a, 1999b), some of which may lead them to wrong their interlocutors, as discussed above. 'Pragmatic-hermeneutical injustice' is here coined in order to focus on the hearer, who is the more or less successful interpreter of discourse and, therefore, the perpetrator of such wronging. This is a(n) (unwanted) result of his processing of ostensive stimuli and, more specifically, of the conclusions he draws when trying to make sense out of communicative behaviour deviating from his expectations and standards in given contexts.

This paper has also argued that epistemic vigilance, and more specifically, a mechanism targeting interpretations which can be labelled hermeneutical vigilance, seems fundamental to avoid making ill-founded attributions of beliefs and PAs when facing pragmatic failures. Although individuals may not always exercise strong or active vigilance, in those cases in which they do so, their vigilance would trigger the enactment of the more complex processing strategy of cautious optimism. Thus, this paper has suggested what the relation and interaction between the suite of epistemic vigilance mechanisms and the relevance-driven comprehension module could be: internal or hermeneutical vigilance could cause the comprehension module to shift processing strategy in order to achieve greater efficiency and avoid undesired conclusions that a less sophisticated processing strategy might yield. Accordingly, cautious optimism turns out to be a strategy that empowers hearers not only to overcome misunderstandings, but also to avoid unwanted side-effects by moving from a position of indiscriminate trust to another of sceptical trust towards interpretations. By so arguing, this paper has stressed the role of cautious optimism in understanding and, more precisely, 
endorsed the opinion that many L2/LF speakers' sophistication in understanding may not be the same as that of native speakers of a language (Garcés Conejos and Bou Franch, 2002). This suggests some avenues for future research.

Children do not gullibly trust any kind of communicated information: they can identify words inappropriately used and contradict and correct assertions that they believe to be false by the age of two (Heyman, 2008; Koenig and Harris, 2007). By the age of three, children seem to prefer individuals whom they consider benevolent and competent on the basis of their own observations and past experiences, as well as other people's reports and comments on those individuals' trustworthiness (Clément et al., 2004; Mascaro and Sperber, 2009). Likewise, by that age children also seem to be able to compare information sources in terms of their reliability and to allocate greater or lesser credibility to other individuals depending on whether they appear to be knowledgeable (Corriveau and Harris, 2009; Koenig and Harris, 2007). By the age of four, children seem to have developed a critical alertness towards dishonesty and incompetence and, therefore, can centre on the truthfulness or falsity of other individuals' messages (Figueras Costa and Harris, 2001; Mascaro and Sperber, 2009). It would be interesting to investigate at which age children show signs of exercising some vigilance towards communication problems like the pragmatic failures stemming from other individuals' diverging or poor pragmatic performance and the misunderstandings they might experience. Investigating this could shed some light onto when children show evidence that they can shift from naïve optimism to cautious optimism and thus abandon a position of indiscriminate trust in comprehension in favour of a position of sceptical trust. Investigating this would also provide us with a fuller picture of children's cognitive development and their performance in situations in which they do not have to deal with deception, false beliefs or erroneous knowledge, but with inappropriate language use and accidentally (ir)relevant interpretations. 
Concerning non-native speakers, it would be illuminating to investigate whether L2 learners and LF users of all ages and types tend to exercise strong, moderate or weak vigilance or whether their vigilance to problems pertaining to communication needs adjusting. Owing to its genetically determined nature, it seems reasonable to assume that all individuals are endowed with the mechanisms of vigilance (Sperber et al., 2010) and that they can transfer or incorporate them into their $\mathrm{L} 2 / \mathrm{LF}$ pragmatics, just as they transfer other mechanisms and abilities intervening in language production and comprehension, such as inference or the skill to adequate messages to context (Kasper, 1997). Indeed, as multicompetent individuals, their performance in their L2/LF would rely on shared usage of such mechanisms and abilities (Cook, 1992, 1999). However, depending on their degree of proficiency in the L2/LF or learning stage, their vigilance might need adjustments or be hindered by the allocation of cognitive resources and effort on other simultaneous processing tasks that might involve some demands, such as discrimination of sounds, syllabification, parsing of syntactic constituents, retention of information in short-term memory or contextualisation of information (Blyth, 2012; Field, 2010; Vandergrift, 1999; Vandergrift and Tafaghodtari, 2010). Similarly, lack of executive control over L2/LF inventory of forms to accomplish some discourse functions (Bialystok, 1993) or excessive reliance on bottom-up processing of linguistic input (Kasper, 1984) might lower the activation of L2 learners and LF users' epistemic vigilance and make them prone to misunderstandings as a result of an excessive focus on form instead of on illocutionary force. If so, it would be illuminating to study how long adjustments in their vigilance would take and which factors are likely to inhibit or slow them down. Moreover, it would be worth exploring if such adjustments may benefit from pedagogical intervention and training, as well as which methods or approaches may be more successful (Kasper and Rose, 2002; Padilla Cruz, 2013b).

Finally, another area that could be researched is the relationship between learners' ego 
boundaries and tolerance of ambiguity and the type of vigilance they tend to exercise or its development. Ego boundaries are a personal characteristic related to the extent to which people compartmentalise their experience by means of internal concepts and are open and receptive to outer influences and unknown situations (Ehrman, 1999; Hartman, 1991). In turn, tolerance of ambiguity is a construct that comprises three levels: intake, or the admission of new information into an individual's mind; tolerance of ambiguity proper, or dealing with contradictory items and incomplete information, and accommodation, or discrimination and integration of new data with already existing information and alteration and/or creation of cognitive structures. Tolerance of ambiguity alludes to the individual's capacity to perceive, understand and react to ambiguous and unfamiliar situations and stimuli (Furnham and Ribchester, 1995). Probably, people with what Ehrman (1999) calls thin ego boundaries and high tolerance of ambiguity are those with an ability to exercise strong vigilance to misinterpretations of divergent linguistic behaviours and an ability to speedily switch to cautious optimism in order to achieve the interpretive friction referred to above and necessary to avoid unwanted effects.

\section{References}

Bachman, L. F., 1990. Fundamental Considerations in Language Testing. Oxford University Press, Oxford.

Barkow, J. H., Cosmides, L., Tooby, J. (Eds.), 1992. The Adapted Mind. Oxford University Press, Oxford.

Baumard, N., André, J. B., Sperber, D., 2013. A mutualistic approach to morality: The evolution of fairness by partner choice. Behavioral and Brain Sciences, 36, 59-78.

Beebe, L. M., Takahashi, T., 1989. Do you have the bag? Social status and patterned variation in second language acquisition. In: Gass, S. et al. (Eds.), Variation in Second Language 
Acquisition, Vol. 1: Discourse and Pragmatics. Multilingual Matters, Clevedon, pp. 103-125.

Beebe, L. M., Takahashi, T., Uliss-Weltz, R., 1990. Pragmatic transfer in ESL refusals. In: Scarcella, R., Andersen, E., Krashen, S. D. (Eds.), Developing Communicative Competence in a Second Language. Newbury House, Rowley, pp. 55-71.

Bialystok, E., 1993. Symbolic representation and attentional control in pragmatic competence. In: Kasper, G., Blum-Kulka, S. (Eds.), Interlanguage Pragmatics. Oxford University Press, New York, pp. 43-59.

Blum-Kulka, S., Olshtain, E., 1986. Too many words: Length of utterance and pragmatic failure. Studies in Second Language Acquisition 8 (2), 165-180.

Blyth, A., 2012. Extensive listening versus listening strategies: Response to Siegel. ELT Journal 66 (2), 236-239.

Boxer, D., 2002 Discourse issues in cross-cultural pragmatics. Annual Review of Applied Linguistics 22, 150-167.

Brown, P., Levinson, S. C., 1987. Politeness: Some Universals in Language Usage. Cambridge University Press, Cambridge.

Canale, M., 1983. From communicative competence to communicative language pedagogy. In: Richards, J. C., Schmidt, R. W. (Eds.), Language and Communication. Longman, London, pp. 2-28.

Canale, M., Swain, M., 1980. Theoretical bases of communicative approaches to second language teaching and testing. Applied Linguistics 1, 1-47.

Carston, R., 2002. Thoughts and Utterances. The Pragmatics of Explicit Communication. Blackwell, Oxford.

Celce-Murcia, M., Dörnyei, Z., Thurrell, S., 1995. Communicative competence: A pedagogically motivated model with content modifications. Issues in Applied Linguistics 5, $5-35$. 
Chen, R., 1993. Responding to compliments. A contrastive study of politeness strategies between American English and Chinese speakers. Journal of Pragmatics 20 (1), 49-75.

Clément, F., Koenig, M., Harris, P., 2004. The ontogeny of trust. Mind \& Language 19 (4), 360-379.

Coady, D., 2010. Two concepts of epistemic injustice. Episteme 7 (2), 101-113.

Cook, V. J., 1992. Evidence for multicompetence. Language Learning 42 (4), 557-591.

Cook, V. J., 1999. Going beyond the native speaker in language teaching. TESOL Quarterly $33(2), 185-209$.

Corriveau, K., Harris, P., 2009. Preschoolers continue to trust a more accurate informant 1 week after exposure to accuracy information. Developmental Science 12 (1), 188-193.

Deterding, D., 2013. Misunderstandings in English as a Lingua Franca. An Analysis of ELF Interactions in South-East Asia. Mouton de Gruyter, Berlin.

Ehrman, M., 1999. Ego boundaries and tolerance of ambiguity in second language learning. In: Arnold, J. (Ed.), Affect in Language Learning. Cambridge University Press, Cambridge, pp. 68-86.

Escandell Vidal, V., 1996. Towards a cognitive approach to politeness. Language Sciences $18,629-650$.

Escandell Vidal, V., 1998. Politeness: A relevant issue for relevance theory. Revista Alicantina de Estudios Ingleses 11, 45-57.

Escandell Vidal, V., 2004. Norms and principles. Putting social and cognitive pragmatics together. In: Márquez-Reiter, R., Placencia, M. E. (Eds.), Current Trends in the Pragmatics of Spanish. John Benjamins, Amsterdam, pp. 347-371.

Field, J., 2010. Listening in the language classroom. ELT Journal 64 (3), 331-333.

Field, R. W., 2007. Pragmatic failure and the attribution of belief. Journal of Philosophical Research 32, 133-143. 
Figueras Costa, B., Harris, P., 2001. Theory of mind development in deaf children: A nonverbal test of false-belief understanding. Journal of Deaf Studies and Deaf Education 6 (2), 92-102.

Fricker, M., 1998. Rational authority and social power: Towards a truly social epistemology. Proceedings of the Aristotelian Society 98 (2), 159-177.

Fricker, M., 2003. Epistemic injustice and a role for virtue in the politics of knowing. Metaphilosophy 34 (1-2), 154-173.

Fricker, M., 2006. Powerlessness and social interpretation. Episteme, A Journal of Social Epistemology 3 (1-2), 96-108.

Fricker, M., 2007. Epistemic Injustice. Power \& the Ethics of Knowing. Oxford University Press, Oxford.

Furnham, A., Ribchester, T., 1995. Tolerance of ambiguity: A review of the concept, its measurement and applications. Current Psychology 14, 179-199.

Garcés Conejos, P., Bou Franch, P., 2002. A pragmatic account of listenership: Implications for foreign/second language teaching. Revista Alicantina de Estudios Ingleses 15, 81-102.

Garfield, J. L., Peterson, C. C., Perry, T., 2001. Social cognition, language acquisition and the development of theory of mind. Mind \& Language 16 (5), 494-541.

Goldman, A. I., 1999. Knowledge in the Social World. Oxford University Press, Oxford.

Grice, H. P., 1975. Logic and conversation. In: Cole, P., Morgan, J. (Eds.), Syntax and Semantics, Vol. 3: Speech Acts. Academic Press, New York, pp. 41-58.

Hale, S., 1996. Pragmatic considerations in court interpreting. Australian Review of Applied Linguistics 19, 61-72.

Hale, S., 1997. The interpreter on trial. Pragmatics in court interpreting. In: Carr, S. E. et al. (Eds.), The Critical Link: Interpreters in the Community. Papers from the First International Conference on Interpreting in Legal, Health and Social Service Settings. John Benjamins, 
Amsterdam, pp. 201-211.

Han, C., 1992. A comparative study of compliment responses: Korean females in Korean interactions and in English interactions. Working Papers in Educational Linguistics 8 (2), 1731.

Hartman, E., 1991. Boundaries in the Mind: A New Psychology of Personality. Basic Books, New York.

Heyman, G., 2008. Children's critical thinking when learning from others. Current Directions in Psychological Science 17 (5), 344-347.

Hong, W., 1997. Sociopragmatics in language teaching: With examples of Chinese requests. Journal of the Chinese Language Tearchers Association 32, 95-107.

House, J., 1990. Cross-cultural pragmatic failure: From mistranslation to misunderstanding. In: Arntz, R., Thome, G. (Eds.), Übersetzungswissenchaft: Ergebnisse und Perspectiven. Festschrift für Wolfram Wilss. Narr, Tübingen, pp. 315-325.

House, J., Kasper, G., 2000. How to remain a non-native speaker. In: Riemer, C. (Ed.), Kognitive Aspekte des Lehrens und Lernens von Fremdsprachen. Cognitive Aspects of Foreign Language Learning and Teaching. Festschrift fur Willis J. Edmondson zum 60. Geburstag. Narr, Tubingen, pp. 101-118.

Hurley, D. S., 1992. Issues in teaching pragmatics, prosody, and non-verbal communication. Applied Linguistics 13 (3), 259-281.

Jackendoff, R., 1992. Languages of the Mind. MIT Press, Cambridge. Jaworski, A., 1995. 'This is not an empty compliment!' Polish compliments and the expression of solidarity. International Journal of Applied Linguistics 5 (1), 63-94.

Kakavá, C., 1993. Conflicting argumentative strategies in the classroom. In: Alatis, J. E. (Ed.), Georgetown University Roundtable on Languages and Linguistics 1993. Strategic Interaction and Language Acquisition. Georgetown University Press, Washington D.C., pp. 
402-420.

Kasanga, L. A., 2001. Intercultural sociolinguistics and communication research in South Africa: Its relevance to academic settings and the service industry. Southern African Linguistics and Applied Language Studies 19 (3-4), 253-273.

Kasanga, L. A., Lwanga-Lumu, J. C., 2007. Cross-cultural linguistic realisation of politeness: A study of apologies in English and Setswana. Journal of Politeness Research 3 (1), 65-92.

Kasper, G., 1984. Pragmatic comprehension in learner-native speaker discourse. Language Learning 34 (4), 1-20.

Kasper, G., 1992. Pragmatic transfer. Second Language Research 8 (3), 203-231.

Kasper, G., 1997. Can pragmatic competence be taught? University of Hawai'i, Second Language Teaching \& Curriculum Center, http://www.nflrc.hawaii.edu/NetWorks/NW06/ (5 September 2012).

Kasper, G., Blum-Kulka, S. (Eds), 1993. Interlanguage Pragmatics. Oxford University Press, Oxford.

Kasper, G., Rose, K. R., 2002. Pragmatic Development in a Second Language. Blackwell, Malden, MA.

Kecskes, I., Papp, T., 2002. Foreign Language and Mother Tongue. Erlbaum, Mahwah, NJ.

Koenig, M., Harris, P., 2007. The basis of epistemic truth: Reliable testimony or reliable sources? Episteme 4 (3), 264-284.

Laver, J., 1975. Communicative functions of phatic communion. In: Kendon, A., Harris, R. M., Key, M. R. (Eds.), Organisation of Behaviour in Face-to-face Interaction. Mouton de Gruyter, The Hague, pp. 215-238.

Leech, G., 1983. Principles of Pragmatics. Longman, London.

Levine, T. R., 2010. A few transparent liars. Explaining 54\% accuracy in deception detection experiments. In: Salmon, C. T. (Ed.), Communication Yearbook 34. Routledge, New York, 
pp. 41-61.

Levine, T. R., Kim, R. K., 2010. Some considerations for a new theory of deceptive communication. In: McGlone, M. S., Knapp, M. L. (Eds.), The Interplay of Truth and Deception. Routledge, New York, pp. 16-34.

Levine, T. R., Kim, R. K., Hughes, M., 2006. Deception detection accuracy is a predictable linear function of message veracity base-rate: A formal test of Park and Levine's probability model. Communication Monographs 73 (3), 243-260.

Levine, T. R., Kim, R. K., Hamel, L. M., 2010. People lie for a reason: Three experiments documenting the principle of veracity. Communication Research Reports 27 (4), 271-285.

Levine, T. R., Park, H. S., McCornack, S. A., 1999. Accuracy in detecting truths and lies: Documenting the "veracity effect". Communication Monographs 66 (2), 125-144.

Mascaro, O., Sperber, D., 2009. The moral, epistemic, and mindreading components of children's vigilance towards deception. Cognition 112 (3), 367-380.

McGuire, W. J., 1964. Inducing resistance to persuasion: Some contemporary approaches. In: Berkowitz, L. (Ed.), Advances in Experimental Social Psychology. Vol. 1. Academic Press, New York, pp. 191-229.

Medina, J., 2011. The relevance of credibility excess in a proportional view of epistemic injustice: Differential epistemic authority and the social imaginary. Social Epistemology: A Journal of Knowledge, Culture and Policy 25 (1), 15-35.

Mercier, H., Sperber, D., 2011: Why do humans reason? Arguments for an argumentative theory. Behavioral and Brain Sciences 34 (2), 57-111.

Michaelian, K., 2013. The evolution of testimony: Receiver vigilance, speaker honesty and the reliability of communication. Episteme 10 (1), 37-59.

Mustajoki, A., 2012. A speaker-oriented multidimensional approach to risks and causes of miscommunication. Language and Dialogue 2 (2), 216-243. 
Nelson, G. L., Al-Batal, M., Echols, E., 1996. Arabic and English compliment responses: Potential for pragmatic failure. Applied Linguistics 17 (4), 411-432.

Nelson, G. L., El Bakary, W., Al Batal, M., 1996. Egyptian and American compliments: Focus on second language learners. In: Gass, S. M., Neu, J. (Eds.), Speech Acts across Cultures. Challenges to Communication in a Second Language. Mouton de Gruyter, Berlin, pp. $109-128$.

Nickerson, R. S., 1998. Confirmation bias: A ubiquitous phenomenon in many guises. Review of General Psychology 2 (2), 175-220.

Nine-Curt, C. J., 1977. Nonverbal Communication. National Assessment and Dissemination Center for Bilingual Education, Lesley College, Cambridge.

Olshtain, E., Cohen, A. D., 1989. Speech act behaviour across languages. In: Dechert, H. W., Raupach, M. (Eds.), Transfer in Language Production. Ablex, Norwood, pp. 53-67.

Olshtain, E., Cohen, A. D., 1990. The learning of complex speech act behaviour. TESL Canada Journal 7 (2), 45-65.

Origgi, G., 2013. Epistemic injustice and epistemic trust. Social Epistemology: A Journal of Knowledge, Culture and Policy 26 (2), 221-235.

Oswald, S., 2011. From interpretation to consent: Arguments, beliefs and meaning. Discourse Studies 13 (6), 806-814.

Padilla Cruz, M., 2004. Aproximación Pragmática a los Enunciados Fáticos. Enfoque Social y Cognitivo. University of Seville, Seville.

Padilla Cruz, M., 2012a. Cautious optimism in second language learning, or how to make L2 learners more competent hearers. In: Wałaszewska, E., Piskorska A. (Eds.), Relevance Theory: More than Understanding. Cambridge Scholars Publishing, New Castle, pp. 279-303. Padilla Cruz, M., 2012b. Epistemic vigilance, cautious optimism and sophisticated understanding. Research in Language 10 (4), 365-386. 
Padilla Cruz, M., 2013a. Understanding and overcoming pragmatic failure in intercultural communication: From focus on speakers to focus on hearers. International Review of Applied Linguistics in Language Teaching 51 (1), 23-54.

Padilla Cruz, M., 2013b. Metapsychological awareness of comprehension and epistemic vigilance of L2 communication in interlanguage pragmatic development. Journal of Pragmatics 59 (A), 117-135.

Pavlidou, T. S., 1994. Contrasting German-Greek politeness and the consequences. Journal of Pragmatics 21 (5), 487-511.

Pavlidou, T. S., 1998. Greek and German telephone closings: Patterns of confirmation and agreement. Pragmatics 8 (1), 79-94.

Riley, P., 1989. 'Well don't blame me!' On the interpretation of pragmatic errors. In: Oleksy, W. (Ed.), Contrastive Pragmatics. John Benjamins, Amsterdam, pp. 231-249.

Riley, P., 2006. Self-expression and the negotiation of identity in a foreign language. International Journal of Applied Linguistics 16 (3), 295-318.

Roberts, M. J., Newton, E. J., 2001. Inspection times, the change task, and the rapid response selection task. Quarterly Journal of Experimental Psychology. Section A: Human Experimental Psychology 54 (4), 1031-1048.

Scarcella, R., 1979. On speaking politely in a second language. In: Yorio, C., Perkins, K., Schachter, J. (Eds.), On TESOL'79: The Learner in Focus. TESOL, Washington, pp. 275287.

Spencer-Oatey, H. (Ed.), 2000. Culturally Speaking: Managing Rapport through Talk across Cultures. Continuum, London.

Sperber, D., 1994. Understanding verbal understanding. In: Khalfa, J. (Ed.), What Is Intelligence? Cambridge University Press, Cambridge, pp. 179-198.

Sperber, D., 1996. Explaining Culture. A Naturalistic Approach. Blackwell, Oxford. 
Sperber, D., 1997. Intuitive and reflective beliefs. Mind \& Language 12 (1), 67-83.

Sperber, D., 2013. Speakers are honest because hearers are vigilant. Reply to Kourken Michaelian. Episteme 10 (1), 61-71.

Sperber, D., Baumard, N., 2012. Moral reputation: An evolutionary and cognitive perspective. Mind \& Language 27 (5), 495-518.

Sperber, D., Mercier, H., 2012. Reasoning as a social competence. In: Landemore, H., Elster, J. (Eds.), Collective Wisdom: Principles and Mechanisms. Cambridge University Press, Cambridge, pp. 368-392.

Sperber, D., Wilson, D., 1986. Relevance. Communication and Cognition. Blackwell, Oxford. Sperber, D., Wilson, D., 1995. Relevance. Communication and Cognition. $2^{\text {nd }}$ edition. Blackwell, Oxford.

Sperber, D., Clément, F., Heintz, C., Mascaro, O., Mercier, H., Origgi, G., Wilson, D., 2010. Epistemic vigilance. Mind \& Language 25 (4), 359-393.

Takahashi, T., Beebe, L. M., 1987. The development of pragmatic competence by Japanese learners of English. JALT Journal 8, 131-155.

Takahashi, T., Beebe, L. M., 1993. Cross-linguistic influence in the speech act of correction. In: Kasper, G., Blum-Kulka, S. (Eds.), Interlanguage Pragmatics. Oxford University Press, New York, pp. 138-158.

Tannen, D., 1984. The pragmatics of cross-cultural communication. Applied Linguistics 5 (3), 188-195

Taylor, T. J., 1992. Mutual Misunderstanding. Scepticism and the Theorizing of Language and Interpretation. Duke University Press, Durham.

Thomas, J., 1983. Cross-cultural pragmatic failure. Applied Linguistics 4 (2), 91-112.

Thomas, J., 1984. Cross-cultural discourse as 'unequal encounter': Towards a pragmatic analysis. Applied Linguistics 5 (3), 226-235. 
Thomas, J., 1995. Meaning in Interaction. An Introduction to Pragmatics. London: Longman.

Tran, G. Q., 2006. The Nature and Conditions of Pragmatic and Discourse Transfer Investigated Through Naturalized Role-play. Lincom, Muenchen.

Vandergrift, L., 1999. Facilitating second language listening comprehension: Acquiring successful strategies. ELT Journal 53 (3), 168-176.

Vandergrift, L., Tafahodtari, M. H., 2010. Teaching L2 learners how to listen does make a difference: An empirical study. Language Learning 60 (2), 470-497.

Weigand, E., 1999. Misunderstanding: The standard case. Journal of Pragmatics 31 (6), 763 785.

Wierzbicka, A., 1996. Contrastive sociolinguistics and the theory of 'cultural scripts': Chinese vs. English. In: Hellinger, M., Ammon, U. (Eds.), Contrastive Sociolinguistics. Mouton de Gruyter, Berlin, pp. 313-344.

Wharton, T., 2009. Pragmatics and Non-verbal Communication. Cambridge University Press, Cambridge.

Wilson, D., 1999. Metarepresentation in linguistic communication. UCL Working Papers in Linguistics 11, 127-161.

Wilson, D., Sperber, D., 2002. Relevance theory. UCL Working Papers in Linguistics 14, 249-287.

Wilson, D., Sperber, D., 2004. Relevance Theory. In: Horn, L., Ward, G. (eds.), The Handbook of Pragmatics. Blackwell, Oxford, pp. 607-632.

Wolfson, N., 1989. Perspectives: Sociolinguistics and TESOL. Newbury House, New York.

Yus Ramos, F., 1999a. Towards a pragmatic taxonomy of misunderstandings. Revista Canaria de Estudios Ingleses 38, 217-239

Yus Ramos, F., 1999b. Misunderstandings and explicit/implicit communication. Pragmatics 9 (4), 487-517. 
Yus Ramos, F., 2013. An inference-centred analysis of jokes: The Intersecting Circles Model of humorous communication. In: Ruiz Gurillo, L., Alvarado, B. (Eds.), Irony and Humor: Highlights and Genres. John Benjamins, Amsterdam, pp. 59-82.

Zamborlin, C., 2007. Going beyond pragmatic failures: Dissonance in intercultural communication. Intercultural Pragmatics 4 (1), 21-50.

Žegarac, V., 2009. A cognitive pragmatic perspective on communication and culture. In: Spencer-Oatey, H., Franklin, P. (Eds.), Intercultural Interaction: A Multidisciplinary Approach to Intercultural Communication. Palgrave, Basingstoke, pp. 31-53. 